\title{
Çocuklarda Ülseratif Kolit Tanısının Belirlenmesinde Fekal Kalprotektinin Rolü
}

\author{
The Role of Fecal Calprotectin in Investigating Pediatric Ulcerative Colitis
}

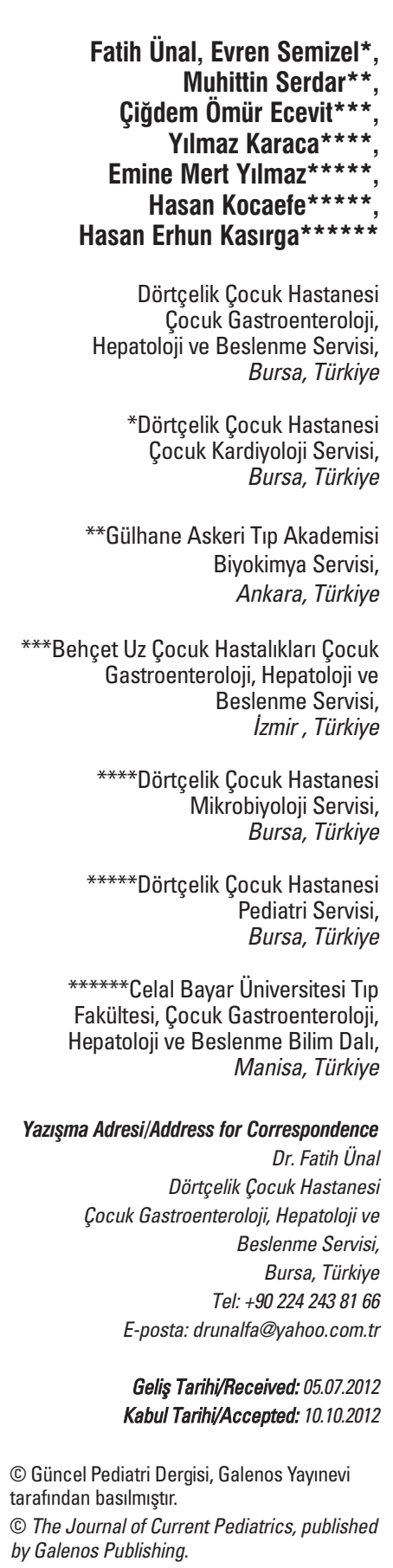

Fatih Ünal, Evren Semizel*, Muhittin Serdar**, Çiğdem Ömür Ecevit***', YIImaz Karaca $* * * *$,

Emine Mert YIImaz ${ }^{* \star * * *}$, Hasan Kocaefe $* * * * *$ Hasan Erhun Kasırga ${ }^{\star * * * * *}$

Dörtçelik Çocuk Hastanesi Çocuk Gastroenteroloji, Hepatoloji ve Beslenme Servisi, Bursa, Türkiye

*Dörtçelik Çocuk Hastanesi Çocuk Kardiyoloji Servisi, Bursa, Türkiye

**Gülhane Askeri Tıp Akademisi Biyokimya Servisi, Ankara, Türkiye

***Behçet Uz Çocuk Hastalıkları Çocuk Gastroenteroloji, Hepatoloji ve Beslenme Servisi, Izmir, Türkiye

****Dörtçelik Çocuk Hastanesi Mikrobiyoloji Servisi, Bursa, Türkiye

*****Dörtçelik Çocuk Hastanesi Pediatri Servisi, Bursa, Türkiye

******Celal Bayar Üniversitesi Tıp Fakültesi, Çocuk Gastroenteroloji, Hepatoloji ve Beslenme Bilim Dali, Manisa, Türkiye

Yazı̧̧ma Adresi/Address for Correspondence Dr. Fatih Ünal Dörtçelik Çocuk Hastanesi Çocuk Gastroenteroloji, Hepatoloji ve Beslenme Servisi, Bursa, Türkiye Tel: +902242438166 E-posta:drunalfa@yahoo.com.tr

Geliş Tarihi/Received: 05.07.2012 Kabul Tarih/Accepted: 10.10.2012

() Güncel Pediatri Dergisi, Galenos Yayınevi tarafindan basilmıştr.

(c) The Journal of Current Pediatrics, published by Galenos Publishing.

\section{ÖZET}

Giriş: Dışkıda fekal kalprotektin (FKP) inflamatuvar bağırsak hastalıklarında (IBBH), bağırsak duvarındaki lökositlerin döngüsünün ve bağırsak lümeni içerisine nötrofillerin migrasyonunun artmasıyla yüksek konsantrasyonlarda bulunabilmektedir. Çalışmamızda ülseratif kolitli (ÜK) hastalarımızda tanı anında FKP değerlerini belirlemeyi ve noninvazif bir yöntem olan bu testin rutin uygulanabilirliğinin etkinliği amaçlanmıştır.

Gereç ve Yöntem: Çalışmamıza tanı konulduğu sırada dışkı örnekleri alınmış olan 19 ÜK'li (10 kız, 9 erkek, yaş ort: $11,5 \pm 3,5$ yıl) ve 20 sağ Ikklı kontrol (10 kız, 10 erkek, yaş ort: 10,3 $\pm 4,5$ yı) dahil edildi. Hastalarımızdan tanı konulduktan hemen sonra, tedavi öncesi, dışkı örnekleri ELISA yöntemi ile FKP çalışılması için toplandı.

Bulgular: ÜK grubunun tamamında FKP değerleri kontrol grubundan anlamlı derecede yüksekti. Dışkıda saptamış olduğumuz FKP değerleri ÜK ve kontrol grubumuzda sırasıyla $398,4(56,7-2450) \mu \mathrm{g} / \mathrm{gr}$ dışkı ve 19,4 (2-81) $\mu \mathrm{g} / \mathrm{gr}$ dışkı olarak bulundu $(\mathrm{p}<0,005)$. ÜK hasta grubumuzun Pediatrik Ülseratif Kolit Aktivite İndeksine (PUCAI) göre hafif aktivite indeksine sahip gruptaki 8 hasta ile orta ve ağır hasta grubunda bulunan 11 hastanın FKP değerleri sırasıyla $267,6(87,4-1690) \mu \mathrm{g} / \mathrm{gr}$ ve $435,2(56,7-2450) \mu \mathrm{g} / \mathrm{gr}$ dışkı olarak bulundu ( $r 2: 0,40, p<0,05)$. Pankoliti olan 11 ve sol kolon, proktit/sigmoidit tutulumu olan 9 hastanın FKP değerleri sırasıyla 422,6 $\mu \mathrm{g} / \mathrm{gr}$ ve $371,7 \mu \mathrm{g} / \mathrm{gr}$ dışkı olarak bulundu, aralarında istatistiki farklılık gözlenmedi ( $>>0,05)$. Diğer akut faz reaktanı olan CRP yüksekliği 15 $(\% 89,4)$, sedimantasyon yüksekliği $16(\% 84,2)$, lökositoz $14(\% 73,6)$, trombositoz 13 $(\% 68,4)$, anemi $15(\% 89,4)$ ve hipoalbüminemi $10(\% 52,6)$ hastada bulundu.

Sonuç: ÜK'li hastalarımızda dışkıda FKP değerlerinin kontrol grubundan anlamlı derecede yüksek olması ve hastalı̆ın aktivitesi arttıkça FKP değerlerinde de artışın gözlenmesi ÜK'li hastalarda FKP'nin tanı ve takip sırasında kullanılmasının yararlı olabileceğini düşündürmüştür. (Güncel Pediatri 2012; 10: 80-4)

Anahtar kelimeler: Ülseratif kolit, fekal kalprotektin, inflamatuvar bağırsak hastalığı

\section{SUMMARY}

Introduction: Fecal calprotectin (FCP) can be found in high concentrations in inflammatory bowel disease due to the increase in leucocyte turnover in intestinal wall or increase of migration of neutrophils into the lumen. In this study, we aimed to determine the FCP values of the ulcerative colitis (UC) patients at the time of diagnosis and to investigate the applicability and effectiveness of this non-invasive method in the diagnosis of the disease, routinely.

Materials and Methods: A total of 19 patients with UC (10 females, 9 males, age: $11.5 \pm 3.5$ years old) whoose stool samples collected during the diagnosis period and 20 healthy controls (10 female, 10 male, age: $10.3 \pm 4.5$ years old) were included in the study. Stool samples were collected for FCP analysis by ELISA method at the time of diagnosis and before the treatment period.

Results: FCP values of the UC group were statistically higher than the control group. FCP values of the UC and control groups were $398.4 \mu \mathrm{g} / \mathrm{gr}$ stool (56.7-2450) and $19.4 \mu \mathrm{g} / \mathrm{gr}$ stool $(2-81)$, respectively $(p<0.005)$. FCP values of the patient group with mild activity index $(n=8)$, and moderate-severe activity index $(n=11)$ according to the Pediatric Ulcerative Colitis 
Activity Index were $267.6-\mu \mathrm{g} / \mathrm{gr}$ stool, and $435.2 \mu \mathrm{g} / \mathrm{gr}$ stool, respectively $(\mathrm{r} 2: 0.40, \mathrm{p}<0.05)$. There was not statistical difference between the FCP values of the patients with pancolitis $(422.6 \mu \mathrm{g} / \mathrm{gr}$ stool) and with left-sided colitis, proctitis/sigmoiditis $(371.7$ $\mu \mathrm{g} / \mathrm{gr}$ stool) (p>0.05). High CRP values $(89.4 \%)$, elevation of erythrocyte sedimentation rate $(84.2 \%)$, leukocytosis $(73.6 \%)$, thrombocytosis $(68.4 \%)$, anemia $(89.4 \%)$, and hypoalbuminemia $(52.6 \%)$ were found.

Conclusions: FCP values of the UC patients were found to be statistically higher than the control group, and increase in FCP values has been observed with increasing disease activity. Therefore, we believe that the determination of FCP could be useful at the time of diagnosis and during follow-up of the patients with UC. (Journal of Current Pediatrics 2012; 10: 80-4)

Key words: Ulcerative colitis, fecal calprotectin, inflammatory bowel disease

\section{Giriș}

Ülseratif kalit (ÜK) remisyon ve aktivasyon periyotları ile seyreden sebebi tam olarak bilinmeyen kronik bir intestinal hastalıktır (1). Son yıllarda inflamatuvar bağırsak hastalıkları (IBH)'nın insidansında ve prevalansında artış görülmektedir. IBH tanısı klinik, laboratuvar, radyolojik, kolonoskopik ve patolojik incelemeler sonucunda konulabilmektedir (1-3). Hastalı̆ın değerlendirilmesinde invazif ve invazif olmayan bazı testler kullanılmaktadır, ancak intestinal inflamasyonu belirlemek için kullanılan Creaktif protein (CRP), sedimentasyon gibi akut faz reaktanları, intestinal hastalı̆ı̆ aktivitesini tam olarak yansıtmamaktadırlar $(4,5)$. Kolonoskopi ve patolojik inceleme inflamasyonu belirlemede en önemli ve güvenilir tanı yöntemi olmakla birlikte invasif ve pahalıdırlar (1). Intestinal inflamasyonu göstermede kullanılan yöntem; ucuz, kolay uygulanabilen, invasif olmayan, bağırsak hastalığının aktivitesini göstermede özgül ve duyarlı bir yöntem olmalıdır $(6,7)$.

Fetal kalprotektin (FKP), immünodülatör, antimikrobiyal ve antiproliferatif özelliği olan, kalsiyum bağlayıcı, nötrofilik sitozolik bir proteindir (8). Inflamasyon ve malign durumlarda beyin omurilik sıvıSı, sinovial sıvı, idrar, dıșkı ve plazmada yüksek konsantrasyonlarda ölçülmektedir (8). FKP, çocuklarda intestinal inflamasyonun gösterilmesinde ve izleminde uygulanabilecek basit, ucuz, duyarl, özgül ve invazif olmayan bir yöntemdir (1,6-8). FKP bağırsağın akut faz reaktanı olarak değerlendirilebilir (6-8). Ayrıca bu belirteç IBH dışında çölyak hastalı̆ı, kolon kanseri, siroz, ilaca bağı enteropati gibi çeşitli hastalıklarda da yüksek olarak saptanmıştır (9-12).

IBH'da FKP değerinde gözlenen yüksekliklerden, bağırsak duvarında lökosit turnoverının artması ve bağırsak lümeni içerisine nötrofillerin migrasyonu sorumlu tutulmaktadır (1). Çalışmamızda yeni tanı almış olan ÜK'li hastalarımızda FKP'nin rolünün belirlenmesi ve pediatrik ülseratif kolit aktivite indeksi (PUCAI), hemogram, CRP, sedimantasyon ve albumin değerleriyle korelasyonunun karşılaştırılması amaçlanmıştır.

\section{Gereç ve Yöntem}

Çalışmamıza Bursa Dörtçelik Çocuk Hastanesi Çocuk Gastroenteroloji, Hepatoloji ve Beslenme bölümünce klinik, laboratuvar, radyolojik, endoskopik ve patolojik incelemeleri sonucunda ÜK tanısı konulan 19 hasta $(10 \mathrm{kIz}$, 9 erkek, yaş ort: $11,5 \pm 3,5$ yaş) ve kontrol grubu olarak genel pediatri ve çocuk kardiyoloji polikliniğimize başvuran yaş ve cinsiyet dağılımı hasta grubu ile uygun olan $20(10 \mathrm{~K}, 10 \mathrm{E}$, yaş ort: $10,3 \pm 4,5$ yaş) sağlıklı çocuk alındı. Tüm örneklerin alınabilmesi için ailelerinden onay alındı. Hasta ve kontrol grubunun akut faz reaktanlarına bakıldı. Dışkı örnekleri giardia, amip ve diğer enfeksiyöz hastalıkları dışlamak için incelendi. Inceleme öncesi son 2 hafta içerisinde nonsteroidal antiinflamatuvar ilaç alanlar, kortikosteroid ve antibiyotik tedavisi almış olanlar ve 4 yaş altı hastalar çalışmaya alınmadı. ÜK'li hasta grubundan hemogram, CRP, sedimentasyon ve albumin gibi tüm tetkikler tanı anında alındı. Hemoglobin değerinin $12 \mathrm{gr} / \mathrm{dl}$ altında olması anemi, lökosit sayısının $10000 / \mathrm{mm}^{3}$ 'ün üzerinde olması lökositoz, trombosit sayısının $400,000 / \mathrm{mm}^{3}$ ün üzerinde olması trombositoz, CRP değerinin 0,8 gr/dl'nin üzerinde olması CRP yüksekliği, sedimentasyon hızının 20 mm/sa'ın üzerinde olması, sedimantasyon yüksekliği ve serum albumin değerinin 3,5 gr/dl'den az olması hipoalbuminemi olarak değerlendirildi. ÜK'li hasta grubunuza tedavi öncesi FKP bakıldı.

Tüm hastalara kolonoskopi ve 14 hastaya ise gastroskopi işlemi yapıldı. Hastaların PUCAI ile hastalık aktivitesi değerlendirildi ve $<35$ altı değerler hafif, 35-64 arasında olan değerler orta ve $65-85$ arası değerler ağır hastalık olarak değerlendirildi. Kolonoskopik bulgulara göre ÜK'li hastalar pankolit ve sol kolon tutulumu olanlar olarak sınıflandırıldı.

FKP ölçümü için hastalardan alınan $5 \mathrm{gr}$ dışkı $-20^{\circ} \mathrm{C}$ 'de saklandı. Tüm örneklerden aynı anda ölçüm yapıldı. Saklanan dışkı örneklerinden 100 mg' $5 \mathrm{ml}$ exbuf ile karıştııılıktan sonra horizontal karıştıııcı ile karıştıııldı, homojenize edildikten sonra santrifuje edildi. Süpernatan ELISA yöntemiyle toplandı (PhilCa| ${ }^{\circledR}$ Calprotectin ELISA 
Kit, Benheim, Almanya). Erişkin ve çocuklar için 0-50 $\mu \mathrm{g} / \mathrm{gr}$ dışkı arası değerler normal, $50 \mu \mathrm{g} / \mathrm{gr}$ 'ın üzerindeki değerler ise pozitif olarak kabul edildi.

Sonuçların değerlendirilmesinde SPSS programının 16,0 (Chicago, IL) sürümü kullanıldı. Değişkenler yüzde olarak ifade edildi. Korelasyon analizleri için Spearman korelasyon analizi, gruplar arasındaki farklılığın önemini vurgulamak için Mann-Whitney U testi kullanıldı.

\section{Bulgular}

Şubat 2009-Haziran 2011 yılları arasında Bursa Dörtçelik Çocuk Hastanesi Çocuk Gastroenteroloji, Hepatoloji ve Beslenme Bölümünde klinik, laboratuvar, kolonoskopik, gastroskopik ve patolojik incelemeleri sonucunda ÜK tanısı konulan 19 hasta ( 10 kız, 9 erkek, yaş ort: $11,5 \pm 3,5$ yaş) ve hiçbir rahatsızlığı olmayan 20 sağ|ıklı çocuk $(10 \mathrm{~K}, 10 \mathrm{E}$, yaş ort:10,3 $\pm 4,5$ yaş) çalışmaya dahil edildi. ÜK tanısı alan 19 hastanın 8 'inde hafif, 7 'sinde orta ve 4 'ünde ise ağır aktivite saptandı.

FKP konsantrasyonu ÜK tanısı konulan 19 hastada tedavi öncesi (\%100) yüksek bulundu. Dışkıda saptanış olduğumuz FKP değeri ÜK'li hasta ve kontrol grubumuzda sırasıyla 398,4 (56,7-2450) $\mu \mathrm{g} / \mathrm{gr}$ dışkı ve 19,4 (2-81) $\mu \mathrm{g} / \mathrm{gr}$ dışkı olarak bulundu. ÜK grubunda FKP değeri, kontrol grubuna göre istatistiksel olarak anlamlı derecede yüksekti $(p<0,005)$. Diğer akut faz reaktanlarından CRP pozitifliği $15(\% 89,4)$, sedimentasyon yüksekliği $16(\% 84,2)$, lökositoz $14(\% 73,6)$, trombositoz $13(\% 68,4)$, anemi 15 $(\% 89,4)$ ve hipoalbuminemi $10(\% 52,6)$ hastada saptandı. Hastalarımızda hastalığın belirteci olan parametrelerden en az 2'si tanı anında pozitifti.

ÜK hasta grubumuzun PUCAI'ne göre hafif aktivite indeksine sahip grup $(n=8)$ ile orta ve ağır hasta grubunda bulunan 11 hastanın FKP değerleri sırasıyla 267,6 $(87,4-1690) \mu \mathrm{g} / \mathrm{gr}$ ve $435,2(56,7-2450) \mu \mathrm{g} / \mathrm{gr}$ dişkı olarak bulundu. Bulunan değerler arasında zayıf korelasyona rastlandı $\left(r^{2}=0,40 ; p<0,05\right)$. Akut faz reaktanları olan hemoglobin, lökosit, CRP, trombosit parametreleri ve albumin düzeyleri arasında bir korelasyon saptanmadı $(p>0,05)$. Kolonoskopik bulgulara göre pankoliti olan $(n=11)$ ve sol kolon tutulumu olan $(n=8)$ hasta gruplarının FKP değerleri sırasılyla 422,6 $\mu \mathrm{g} / \mathrm{gr}$ (96,3-2450)ve 371,7 (56,71759) $\mu \mathrm{g} / \mathrm{gr}$ dışkı olarak bulundu, aralarında istatistiki farklılık gözlenmedi $(p>0,05)$. ÜK'li hastaların demografik özelliklerini, laboratuvar bulgularını, endoskopik bulguları Tablo 1'de, grupların FKP değerleri ise Tablo 2'de özetlenmiştir.

\section{Tartışma}

ÜK remisyon ve aktivasyon periyotları ile giden kronik bağırsak hastalığıdır (1). Hastalığın tanısının konulması yanında hastalığın aktivasyonun ortaya çıkartılması ve tedaviye yanııı bilinmesi açısından özgül laboratuvar belirteçlerine gereksinim vardır $(1,4-6,13)$. Günümüzde ÜK'te intestinal inflamasyonun izlenmesi için sıklıkla lökositoz, trombositoz, CRP ve sedimentasyon değerlerinin PUCAI ile korelasyonunun düşük olduğu bilinmektedir (1,46). Tüm bu nedenlerden dolayı bağırsaklardaki aktiviteyi daha iyi gösterebilecek fekal belirteçler üzerinde durulmaya başlanmışıır. Foell ve ark. (13) çalışmalarında FKP'nin IBH'nın ayırıcı tanısının yapılabilmesinde duyarlıı̆ı \%63-100, özgüllüğü \%79-93, pozitif prediktif değeri \%75-90 ve negatif prediktif değeri \%51-100 olarak bulunmus ve son derece önemli bir belirteç olabileceği belirtilmiştir.

Tablo 1.Ülseratif kolit tanılı hastalarımızın tanı anındaki demografik verileri, kolonoskopik bulguları, laboratuvar ve FKP değerleri

\begin{tabular}{|l|c|}
\hline Yaş (yıl) & $11,35 \pm 3,5$ \\
\hline Cinsiyet (K/E) & $10 / 9$ \\
\hline ÜK yerleşimi (pankolit/ sol kolon) & $11 / 8$ \\
\hline PUCAl (hafif/orta+ ağır) & $8 / 11$ \\
\hline FKP $\mu$ g/gr (n/\%) & $398,4(56,7-2450)(19 / 100)$ \\
\hline Lökosit $>10.000 \mathrm{~mm}^{3}$ (n /\%) & $14(\% 73,6)$ \\
\hline Hb $(<12 \mathrm{gr} / \mathrm{dl})$ & $15(89,4)$ \\
\hline Trombosit $>400.000 ~ \mathrm{~mm}^{3}$ & $13(68,4)$ \\
\hline CRP $(>0,8 \mathrm{mg} / \mathrm{dl})(\mathrm{n} / \%)$ & $15(89,4)$ \\
\hline Sedimantasyon (mm/sa) & $16(84,2)$ \\
\hline Albumin <3,5 gr /dl (n/\%) & $10(52,6)$ \\
\hline \multicolumn{2}{|l|}{ ÜK: Ülseratif kolit, FKP: Fekal kalprotektin, Hb: Hemoglobin, } \\
CRP: C-reaktif protein, PUCAl: Pediatrik ülseratif kolit aktivite indeksi
\end{tabular}

\begin{tabular}{|c|c|c|c|}
\hline & \multicolumn{3}{|c|}{ FKP değerleri $(\mu \mathrm{g} / \mathrm{gr})$} \\
\hline ÜK/ Kontrol & $398,4(56,7-2450)$ & $19,4(2-81)$ & $p<0,005$ \\
\hline PUCAI hafif/orta+ağır & $267,6(87,4-1690)$ & $435(56,7-2450)$ & $r^{2}=0,40 ; p<0,05$ \\
\hline Kolonoskopi pankolit/ sol kolon & $422,6(96,3-2450)$ & 371,7 (567-1759) & $p>0,05$ \\
\hline
\end{tabular}


IBH olan çocuklarda FKP düzeyinin intestinal inflamasyou olmayan kontrol grubu çocuklara göre anlamlı derecede daha yüksek olduğu gösterilmiştir $(3,7,14,15)$. Çalışmamızda tedavi öncesi ÜK'li 19 hastamızın tamamında $(\% 100)$ FKP değerleri kontrol grubu ile karşılaştırıldığında anlamlı derecede yüksek bulunmuş olup bulgularımız literatür ile uyumluydu.

IBH dışında çölyak hastalığı, kolon kanseri, nonsteroid antiinflamatuvar ilaç enteropatisi, kronik pankreatit, siroz gibi hastalıklarda da FKP düzeyleri yüksek tespit edilmiștir (9-12). Ertekin ve ark. (9) çalışmalarında çölyak hastalı̆̆ olan çocuklarda FKP düzeyleri kontrol grubuna göre anlamlı derecede yüksek bulmuşlardır.

Mukozal inflamasyonu belirlenmede FKP güvenilir ve girişimsel olmayan bir tetkiktir (1,6-8). FKP'nin, IBH olan çocuklarda relapsların belirlenmesinde, hastalığın izlemi ve tedaviye yanıtının değerlendirilmesinde endoskopik ve patolojik bulgularla korelasyon içerisinde olduğu gösterilmiştir $(1,3,6-8,14,15)$. Çalışmamızda PUCAI göre orta ve ağır aktivasyona sahip ÜK hasta grubunun FKP değerlerini, hafif aktivasyon gösteren hasta grubundan daha yüksek bulduk, bulgular litaratür ile uyumluydu $(1,15)$. Erbayrak ve ark. (1) erişkin IBH olan hastalarda FKP'nin tedaviye yanıın değerlendirilmesinde ve relapsların erken tanınmasında faydalı olabileceğini göstermiş̧lerdir. Fagerberg ve ark. (15) mukozal inflamasyonun derecesi ile FKP değerleri arasında ilişkinin olduğunu ve noninvazif bir tetkik olarak kullanılabileceğini belirtmişlerdir. Canani ve ark. (16) da yapmış oldukları çalışmada IBH'da FKP'nin noninvazif bir belirteç olarak kullanılabileceğini belirtmişlerdir. Uslu ve ark. (6) ise yapmış oldukları çalışmada IBH'lı pediatrik hasta gruplarında, hastalı̆ın aktivasyonu ile FKP arası ilişkiye rastlamazlarken, trombositoz ile FKP arası ilişki olabileceğini göstermişleridir. Çalışmamızda FKP değerleri ile hastalı̆ın göstergeleri olan akut faz reaktanları arasında ilişkiye rastlayamadık; bunun nedeni çalışma grubumuzdaki ÜK'li hasta sayısının azı̆̆ı olabilir.

Quail ve ark. (17) yapmış olduğu çalışmada IBH tanısı konulmuş 48 çocuk hastanın değerlendirilmesinde hastaların \%96'sında FKP değerlerini $(750 \mu \mathrm{g} / \mathrm{gr}$ dışkı) yüksek olarak bulmuşlardır. FKP diğer rutin laboratuvar değerlerinden daha fazla yükselmektedir. FKP'nin diğer akut faz reaktanlarıyla birlikte kullanılmasının çocukluk çağı İBH hastalığının tanı ve izleminde kullanılabileceğini belirtilmişlerdir. Uslu ve ark. (6) kendi hasta gruplarında \%95 oranında FKP yüksekliğine rastlamışlardır. Çalışmamızda ÜK hasta grubunda FKP değerlerinde rastlanan yükseklikler literatür ile uyumluydu $(6,17)$. IBH'da tanı anında hastalığın göstergeleri olan akut faz reaktanları her zaman yüksek olmayabilir $(6,18)$. Biz de çalışmamızda tanı anındaki akut faz reaktan yüksekliğine, ÜK'li hastaların hepsinde rastlayamadık ve bu bulgular literatür ile uyumluydu $(6,18)$.

Canani ve ark. (19) çalışmalarında IBH ön tanısı ile polikliniklerine başvuran hastalarda, perinükleer antinötrofilik antikor, anti-saccharomyces cerevisiae antikor, FKP, incebağırsak geçirgenlik testi ve ultrasonografik olarak incebağırsak kalınlı̆ı ölçümünün hep birlikte değerlendirilmesiyle noninvaziv olarak tanı konulmasının mümkün olabileceğini belirtmişlerdir. Beattie ve ark. (20) ise kronik karın ağrısı yanında kanlı mukuslü ishali, ateşi ve kilo kaybı ve ağızda iyileşmeyen yara bulguları olan 39 çocuğun 26'sında Crohn hastalığı tanısı koymuşlar, tüm hastalarda CRP değerlerini yüksek olarak bulmuşlardır.

Sonuç olarak, çalışmamız az sayıda yeni tanı almış olan ÜK'li hasta üzerinde yapıldı; tüm hastalarda FKP değerleri yüksek bulundu; PUCAI göre orta ve ağır grubu oluşturan hastalarda FKP değerleri, hafif tutulum gösteren olgulardan yüksekti; akut faz reaktanları hastalığa tanı konulduğu sırada her zaman yüksek bulunmamaktadır. Invazif olmayan ve hastalığı belirlemede hassas bir gösterge olan FKP testinin ÜK'in tanı ve takibinde rutinde kullanılabilirliğinin artacağı düşüncesindeyiz.

\section{Kaynaklar}

1. Erbayrak M, Turkay C, Eraslan E, Çetinkaya H, Kasapoğlu B, Bektaş M. The role of fecal calprotectin in investigating inflamatory bowel diseases. Clinics (Sao Paulo) 2009;64:421-5.

2. Kugathasan S, Judd RH, Hoffmann RG, Heikenen J, Telega G, Khan $F$ et al. Epidemiologic and clinical charecteristics of children with newly diagnosed inflamatory bowel disease in Wisconsin: a statewide population-based study. J Pediatr 2003;143:525-31.

3. Gisbert JP, Bermejo F, Perez-Calle JL, Taxonera C, Vera I, McNicholl AG, et al. Fecal calprotectin and lactoferrin for the prediction of inflammatory bowel disease relapse. Inflamm Bowel Dis 2009;15:1190-8.

4. North American Society for Pediatric Gastroenterology, Hepatology, and Nutrition; Colitis Foundation of America, Bousvaros A, Antonioli DA, Colletti RB, Dubinsky MC, et al. Differentiating ulcerative colitis from Crohn disease in children and young adults: report of a working group of the North American Society for Pediatric Gastroenterology, Hepatology, and Nutrition and the Crohn's and Colitis Foundation of America. J Pediatr Gastroenterol Nutr 2007;44:653-74.

5. Mack DR, Langton C, Markowitz J, LeLeiko N, Griffiths A, Bousvaros $A$, et al. Laboratory values for children with newly diagnosed inflamatory bowel disease. Pediatrics 2007;119: 1113-9.

6. Uslu N, Baysoy G, Balamtekin N, Hızal G, Demir H, SaltıkTemizel İN, ve ark. Çocuklarda enflamatuar bağırsak hastalığı tanısında noninvasif bir belirteç: fekal kalprotektin. Çocuk Sağlığı ve Hastalıkları Dergisi 2011;54:22-7. 
7. Vermeire S, Van Assche G, Rutgeerts P. Laboratory markers in IBD: Useful magic or unnecessary toys. Gut 2006;55:426-31.

8. Fagerhol MK, Dale I, Andersson T. Release and quantitation of a lycocyte derived protein (L1). Scand J Heamatol 1980;24:393-8.

9. Ertekin V, Selimoğlu MA, Turgut A, Bakan N. Fecal calprotectin concetrationin celiac disease. J Clin Gastroenterol 2010;44:544-6.

10. Johne B, Kronborg O, Ton HI, Kristinsson J, Fuglerud P. A new fecal calprotectin test for colorectal neoplasia. Cinical results and comparison with previous method. Scand J Gastroenterol 2001;36:291-6.

11. Tibble JA, Sigthorsson G, Foster R, Scott D, Fagerhol MK, Roseth $A$, et al. High prevalence of NSAID enteropathy as shown by a simple faecal test. Gut 1999;45:362-6.

12. Carroccio $A$, lacono $G$, Cottone $M$, Prima $L D$, Cartabellotta $F$ Cavataio $F$, et al. Diagnostic accuracy of fecal calprotectin assay in distinguishing organic causes of chronic diarrhea from irritable bowel syndrome: a prospective study in adults and children. Clin Chem 2003;49:861-7.

13. Foell D, Wittkowski $H$, Roth J. Monitoring disease activity by stool analyses: from occult blood to molecular markers of intestinal inflamation and damage. Gut 2009;58:859-68.

14. Kolho KL, Raivo $T$, Lindahl $H$, savilahti $E$. Fecal calprotectin remains high during glucorticoid theraphy in children inflamatory bowel disease. Scand J Gastroenterol 2006;41:720-5.
15. Fagerberg UL, Lööf L, Myrdal U, Hansson LO, Finkel Y. Colorectal inflamation is well predicted by fecal calprotectin in children with gastrointestinal symptoms. J Pedatir Gastroenterol Nutr 2005;40:450-5.

16. Canani RB, Terrin G, Rapacciuolo L, Miele E, Siani MC, Puzone $C$, et al. Feacal calprotectin as reliable non-invazive marker to accesi the severety of mukozal inflamation in children with inflamatory bowel disease. Dig Liver Dis 2008;40:547-53.

17. Quail MA, Russell RK, Van Limbergen JE, Rogers P, Drummond $\mathrm{HE}$, Wilson DC, et al. Fecal calprotectin complements routine laboratory investigations in diagnosing childhood inflamatory bowel disease. Inflam Bowel Dis 2009;15:756-9.

18. Mack DR, Langton C, Markowitz J, LeLeiko N, Griffiths A, Bousvaros $A$, et al. Laboratory values for children with newly diagnosed inflamatory bowel disease. Pediatrics 2007;119:1113-9.

19. Canani RB, Horatio LT, Terrin G, Romano MT, Miele E, Staiano $A$, et al. Combined use of noninvasive tests useful in the initial diagnostic approach to a child with suspected inflammatory bowel disease. J Pediatr Gastroenterol Nutr 2006;42:9-15.

20. Beattie RM, Walker-Smith JA, Murch SH. Indications for invastigation of chronic gastrointestinal symptoms. Arch Dis Child 1995;73:354-5. 